\title{
A Cognitive Behavioural Therapy Pain Management Programme for Neuropathic Pain Post Spinal Cord Injury: A Feasibility Study Including the Clinician and Patient Perspectives
}

\author{
Burke $D^{1 *}$, Lennon $\mathbf{O}^{1}$, Nolan $\mathrm{M}^{2}$, Barry $\mathrm{S}^{2}$, Smith \\ $E^{2}$, Maye $F^{2}$, Mc Phillips $B^{2}$, Ní Ghiollain $S^{2}$ and \\ Fullen BM ${ }^{1,3}$ \\ ${ }^{1}$ UCD School of Public Health, Physiotherapy and Sports \\ Science, Health Science Centre, University College \\ Dublin, Belfield, Dublin, Ireland \\ ${ }^{2}$ The Spinal Cord System of Care Team, The National \\ Rehabilitation Hospital Roches town Avenue, Dun \\ Laoighre, County Dublin, Ireland \\ ${ }^{3}$ UCD Centre for Translational Pain Research, University \\ College Dublin, Belfield, Dublin, Ireland \\ *Corresponding author: Dearbhla Burke, UCD School \\ of Public Health, Physiotherapy and Sports Science, \\ Health Science Centre, University College Dublin, \\ Belfield, Dublin, Ireland
}

Received: July 03, 2017; Accepted: July 28, 2017; Published: August 04, 2017

\begin{abstract}
Objective: To evaluate the feasibility of a cognitive behavioural therapy pain management programme for managing neuropathic pain post-spinal cord injury.

Design: A mixed methods prospective feasibility trial.

Setting: A national rehabilitation hospital.

Subjects: Adults with neuropathic pain post-spinal cord injury.

Methods: Following ethical approval, participants were recruited from a spinal cord injury outpatient service. A multi-disciplinary team delivered the programme twice a week over five weeks. Changes in study outcome measures addressing quality of life, mood and sleep indices over three time periods were analysed using Friedman's test. Differences from baseline to intervention completion and six months follow-up intervals were analysed using Wilcoxon sign-rank test. Significance was set $p<0.05$. Post-intervention qualitative feedback was obtained from programme participants and the clinicians involved.

Results: Eight participants completed the programme. Significant improvements were noted post-intervention in the psychological domain of the World Health Organisation Quality of Life Bref $(Z=-2.120 ; p=0.03)$ and the depression score $(Z=-2.555 ; p=0.01)$ of the Hospital Anxiety and Depression Scale, remaining significantly improved at six months follow-up when compared to baseline $(Z=-2.533 ; p=0.01)$. Transportation was the main barrier to recruitment. Qualitative feedback highlighted the positive impact for participants in coping with pain. Clinicians noted many positive outcomes of the programme, whilst highlighting health-systems difficulties in implementation.
\end{abstract}

Conclusions: A cognitive behavioural therapy pain management programme is perceived as beneficial by individuals with neuropathic pain after spinal cord injury, a finding supported by quantitative data analysis. Recruitment barriers to programme delivery indicate that alternate modes of delivery warrant consideration.

Keywords: Spinal cord injury; Cognitive behavioural therapy pain management programme; Neuropathic pain; Chronic pain; Chronic pain selfmanagement

\section{Abbreviations}

AIS: American Spinal Injury Association Impairment Scale; CBT: Cognitive Behavioural Therapy; HADS: Hospital Anxiety and Depression Scale; HRQoL: Health Related Quality of Life; ln: Line in Transcript; MDT: Multi-disciplinary Team; NP: Neuropathic Pain; NRH: National Rehabilitation Hospital; PMP: Pain Management Programme; PSQI: Pittsburgh Sleep Quality Index; SCI: Spinal Cord Injury; S: Speaker, t1: Pre-Intervention; t2: Post-intervention, t3: Six month follow up; WHOQOL-BREF: World Health Organisation Quality of Life Bref.

\section{Introduction}

Chronic pain, a common sequela after spinal cord injury (SCI) [1], is perceived as a particularly challenging complication to address, along with urinary tract infections, pressure ulcers and spasticity $[2,3]$. It results in poorer quality of life [4], depression [5] and sleep disturbances [6]. Presentations of nociceptive pain (musculoskeletal, visceral and other) and neuropathic pain (at level, below level and other) may simultaneously co-exist post-injury [7]. However, neuropathic pain (NP) post-SCI is cited as the most severe and disturbing pain $[7,8]$ with a high pooled prevalence of $53 \%$ reported [9].
Phys Med Rehabil Int - Volume 4 Issue 3 - 2017 ISSN : 2471-0377 | www.austinpublishing group.com Burke et al. (C) All rights are reserved
Citation: Burke D, Lennon O, Nolan M, Psych DC, Barry S, Smith E, et al. A Cognitive Behavioural Therapy Pain Management Programme for Neuropathic Pain Post Spinal Cord Injury: A Feasibility Study Including the Clinician and Patient Perspectives. Phys Med Rehabil Int. 2017; 4(3): 1119. 
Recent guidelines in NP post-SCI management advocate a multi-disciplinary approach with medical, physical, educational and cognitive-behavioural components, addressing the wider functional and psychological impact [10]. Management, it is proposed, should be patient-centred, goal-directed and functional; treating the patient holistically and including significant others in the process, where appropriate [10]. Whilst the efficacy of multidisciplinary pain management programmes (MDT-PMPs) based on a biopsychosocial approach is well established [11], minimal research addresses chronic pain management post-SCI. A PMP specific to SCI is optimal as adaptations are required to the traditional PMP structure based on participants' complex needs; personal care routines, reduced activity tolerance and modification of exercise-based components [12]. As per recommendations, this requires expertise in SCI rehabilitation and a dedicated unit for optimal delivery [13]. In addition, coping and adjustment benefits from interaction with peers also experiencing SCI related pain, is significant [14].

Quantitative research dominates the contemporary literature [15-18] addressing the efficacy of CBT-PMPs in adults with SCI chronic pain. Results demonstrate reductions in pain catastrophizing [18], pain interference [15], pain intensity, pain related disability, life satisfaction, anxiety and depression [16-18]. However, pain is a subjective, individual experience, only known to the person who suffers [19]. Despite this, qualitative studies remain under-represented in chronic pain literature [20]. This methodology is gaining increased recognition now in the investigation and understanding of the SCI pain experience from the individual's perspective, an aspect often in accessible by alternate methods [21,22]. Advancement of chronic pain management furthermore requires documentation of the clinicians' perspectives [23]. To date qualitative studies detailing the experience of completing a SCI CBT-PMP $[17,18]$ have been limited to short written comments relating to participants' experience of their CBT-PMP [18] and documenting overall perceptions of the intervention, focusing on programme length and delivery [16,17]. No study has evaluated other stakeholders' perspectives (e.g. clinicians) on developing and delivering a PMP in a SCI rehabilitation unit.

No recommended timeframe for conducting a CBT-PMP exists as, it is argued, intensity and length should vary based on participants' health needs and requirements [24]. However, a review of randomised controlled trials of self-management programmes for chronic musculoskeletal pain found longer interventions did not necessarily produce better outcomes [25]. Previous CBT-PMPs for SCI pain ranged in length from eight [18] to ten weeks [15,17,26], with programme contact hours ranging from 33 [16] to 50 hours [15,17]. A shorter, condensed CBT-PMP has yet to be evaluated and warrants consideration given recruitment issues [17,18], reduced activity tolerance, mobility restrictions and inherent transport barriers $[12,15]$ reported in previous studies of CBT-PMPs in SCI. Hence this study aims to establish the feasibility and efficacy of a shorter, more intensive CBT-PMP in subjects with chronic NP post-SCI and garner broad stakeholder perspectives that include participants' experience as well as clinicians' perspectives relating to programme development and delivery.

\section{Methods}

\section{Study design}

This mixed methods prospective feasibility trial involved community dwelling adults with diagnosed NP post-SCI. Phase 1 involved participants attending a SCI tailored CBT-PMP twice a week for five weeks. Quantitative outcome measures (pain, quality of life, mood, and sleep indices) were collected at baseline, post-intervention and six months post CBT-PMP completion. In Phase 2 qualitative data (semi-structured telephone interviews) were collected relating to individuals' experiences of participating in the programme. A focus group of clinicians involved in the design and delivery of the programme was also conducted to explore their experiences of devising and rolling out the CBT-PMP and to gain insights for future programme sustainability.

\section{Recruitment and inclusion criteria}

Following ethical approval from the National Rehabilitation Hospital (NRH) Ethics Committee, participants with a documented NP diagnosis were recruited through the NRH outpatient clinic. This is the only dedicated clinic for community dwelling adults with a SCI in the Republic of Ireland. Written and informed consent was obtained from each participant.

Potential participants were sent information about the study (Phase 1 and Phase 2). Inclusion criteria in phase 1 included SCI American Spinal Injury Association Impairment Scale (AIS) score A-C [27], discharge from acute hospital and rehabilitation services, diagnosis of chronic NP (pain greater than three months, confirmed by a rehabilitation medicine consultant), over 18 years of age, with fluent English (verbal and written) and the ability to attend a five week programme in Dublin.

Exclusion criteria included AIS D-E, acute injury under specialist medical care, any ongoing medico-legal cases and any confounding co-morbidities including cancer, unstable angina, uncontrolled cardiac arrhythmias, severe aortic stenosis, acute systemic infection accompanied by fever, systemic or inflammatory diseases, substance abuse, significant mental health issues or inability to provide informed consent. Following screening, a consent form and battery of validated questionnaires were sent by post, one week prior to programme commencement. All clinicians involved in the planning and delivery of the programme were invited to participate in a focus group following programme completion.

\section{Phase 1: The intervention}

The CBT-PMP ran twice weekly for five weeks (10am-14:45pm) with 3.5 daily contact hours. The programme was adapted from the empirically tested Ulysses CBT-PMP by SCI rehabilitation specialists from medicine, clinical psychology, physiotherapy, occupational therapy, dietetics, social work, nursing and clinicians involved in the Ulysses CBT-PMP [28], guided by Perry et al. [12]. Adaptations of the Ulysses CBT-PMP [28] facilitated the anticipated requirements of individuals with SCI. Weekly sessions were reduced from three days a week to two days per week and length of delivery increased from four to five weeks. The exercise component was modified to reflect current best practice as delivered by the NRH with exercises adapted to suit the individual needs of the participants with varying SCI presentations. Sessions involving goal setting placed less emphasis on reduction of mobility aid use and return to full time employment; instead participants were encouraged to pursue goals relevant and applicable to their life after SCI. Pain education sessions were modified to include information on SCI pain mechanisms and classification. 
Table 1: Overview of Programme Content.

\begin{tabular}{|c|c|}
\hline Session & Content Covered \\
\hline 1 & $\begin{array}{l}\text { Introduction to team } \\
\text { Living with pain after SCI (Psychology) } \\
\text { Physiotherapy exercise session } \\
\text { Individual keyworker session } \\
\text { Relaxation introduction }\end{array}$ \\
\hline 2 & $\begin{array}{l}\text { Understanding pain after } \mathrm{SCl} \\
\mathrm{CBT} \text { and pain } \\
\text { Physiotherapy exercise session } \\
\text { Medical aspects of pain and } \mathrm{SCl} \text { (Consultant) } \\
\text { Relaxation practice }\end{array}$ \\
\hline 3 & $\begin{array}{l}\text { Individual Keyworker session } \\
\text { Physiotherapy exercise session } \\
\text { Pain medicine (Pharmacy) } \\
\text { Relaxation practice }\end{array}$ \\
\hline 4 & $\begin{array}{l}\text { Physical activity posture \& exercise (Physiotherapy) } \\
\text { Physiotherapy exercise session } \\
\text { Pacing \& goal setting (Psychology) } \\
\text { Relaxation practice }\end{array}$ \\
\hline 5 & $\begin{array}{l}\text { Pain, thoughts and feelings (Psychology) } \\
\text { Physiotherapy exercise session } \\
\text { Assertive communication (Psychology) } \\
\text { Relaxation practice }\end{array}$ \\
\hline 6 & $\begin{array}{l}\text { Family Session } \\
\text { Physiotherapy exercise session } \\
\text { Lifestyle and nutrition (Dietician/ Physiotherapy) } \\
\text { Relaxation practice }\end{array}$ \\
\hline 7 & $\begin{array}{l}\text { Sleep hygiene and fatigue (Occupational Therapy) } \\
\text { Physiotherapy exercise session } \\
\text { Individual Keyworker session } \\
\text { Relaxation practice }\end{array}$ \\
\hline 8 & $\begin{array}{l}\text { Support networks (Psychology) } \\
\text { Physiotherapy exercise session } \\
\text { Managing pain at home (Occupational Therapy) } \\
\text { Relaxation practice }\end{array}$ \\
\hline 9 & $\begin{array}{l}\text { Pain quiz (Physiotherapy/ Psychology) } \\
\text { Physiotherapy exercise session } \\
\text { Pain flare up management (Psychology) } \\
\text { Relaxation practice }\end{array}$ \\
\hline 10 & $\begin{array}{l}\text { Leisure activities and pain (Physiotherapy) } \\
\text { Physiotherapy exercise session } \\
\text { Relaxation practice } \\
\text { Evaluation and farewell }\end{array}$ \\
\hline
\end{tabular}

Less importance was placed on the reduction of pain medication use throughout the programme and as an alternative, education was provided regarding medications recommended in the management of SCI pain, similar to Perry et al. [12]. Participants enrolled in the trial were asked to refrain from altering current medications for the duration of the CBT-PMP.

The CBT-PMP content, summarised in Table 1, was based on principles of Fordyce [29] and Turk [30] and incorporated operant and cognitive behavioural principles. It comprised daily group psychology sessions focusing on CBT principles and using cognitive techniques to identify unhelpful and unrealistic thoughts and beliefs related to pain and to challenge and change them. Daily group relaxation sessions were completed in addition to gym-based physiotherapy sessions with a patient-driven progressive programme modified for each individual's ability. Goal setting by participants was encouraged throughout the programme to aid the incorporation of learned CBT techniques into daily life. Three key worker sessions took place over the course of the programme where participants had the opportunity to meet individually with an allied healthcare professional. These sessions explored in more detail goal setting and personal issues surrounding NP that the participant may not have wished to share in a group setting.

Educational sessions (two hours duration per week) were delivered across a range of topics including mechanisms of NP after SCI, explanations of the pain gate control theory, the impact of CBT strategies on the perception of pain, discussion of medication use, stress management and pacing strategies for activities of daily living. A manual which supported all components of the programme was provided. A family session during week three of the programme afforded family members or close friends the opportunity to meet members of the CBT-PMP team and learn about the programme aims and content, and how they could support the participant in managing their pain better.

\section{Study instruments}

Outcome measures were assessed at baseline (t1), postintervention ( $\mathrm{t} 2$ ) and six months post programme completion ( $\mathrm{t} 3$ ). They included self-assessed measure of health related quality of life (HRQoL), pain, mood and sleep quality. Demographic details and SCI characteristics were collated. These are detailed below.

Demographics and SCI characteristics: Demographic characteristics recorded included age, gender, employment and relationship status. Spinal cord injury characteristics recorded included the year and cause of injury, the neurological level of injury (NLI), the American Spinal Injury Association Impairment Scale (AIS) [27], and whether surgical management post-injury was used. Mobility status and access to a motor vehicle was recorded.

Health related quality of life: The primary outcome measure was HRQoL as measured by the WHOQOL-BREF [31]. This selfreported questionnaire, validated in this patient population [32,33], is recommend as the optimal HRQoL measure post-SCI [34]. The scale includes 26 questions and scores are calculated into four weighted domains (0-100) of physical health, psychological health, social relationships, and environmental relationships. Higher scores indicate better HRQoL [31].

Pain: Pain was measured by the International Spinal Cord Injury Pain Basic Dataset (ISCIPBDS) (Version 1) validated for selfreported use in the SCI population [35]. In addition to a numeric rating scale for pain intensity, it includes questions on pain frequency and location, and six pain interference items covering sleep, mood and activity limitations [35].

Mood: Mood was measured by the Hospital Anxiety and Depression Scale [36]. This scale has shown good internal consistency and content validity in community dwelling individuals with SCI [37]. Higher scores indicate more emotional distress, scores of 0-7 (absence of trait), scores of between 8 and 10 classified as being 'at risk' of developing trait and greater than 11 as having the trait [36].

Sleep: Sleep was measured using the Pittsburgh Sleep Quality Index, a validated tool [38], with previous application to SCI clinical research [39]. It assesses sleep quality and disturbances in the previous month. Nineteen items are calculated into seven component scores which then total to one global score. A global score greater than 5 is indicative of poor sleep quality [38]. 
Table 2: Questions from Interviews with Participants and Clinicians.

\begin{tabular}{|c|c|}
\hline \multicolumn{2}{|r|}{ Questions from Semi-structured Interviews with Participants } \\
\hline General Feedback & $\begin{array}{l}\text { What did you think of the programme overall? } \\
\text { Was there any part or parts of the programme you found particularly useful/ could be improved? }\end{array}$ \\
\hline Pain Knowledge and Attitude & $\begin{array}{l}\text { What is your understanding of what } \mathrm{SCl} \text { chronic pain is now? } \\
\text { Do you continue to use any pain management strategies or what pain strategies are useful? } \\
\text { Has your ability to cope with you pain changed since the programme? }\end{array}$ \\
\hline Impact on daily life & $\begin{array}{l}\text { Has your quality of life/ mood/ sleeping patterns changed due to the programme? } \\
\text { Do you think the CBT-PMP has made an impact on family friends? }\end{array}$ \\
\hline Future Programmes & $\begin{array}{l}\text { What advice would you give us If we were to run this programme again? } \\
\text { When do you think would be the best time after a spinal cord injury to do a PMP? } \\
\text { If you were unable to attend a hospital pain programme would you engage with an online version of the programme? }\end{array}$ \\
\hline \multicolumn{2}{|r|}{ Questions from the Focus Group with Clinicians } \\
\hline Development of Programme & $\begin{array}{l}\text { How did you find preparing for the PMP? } \\
\text { What difficulties arose in the preparation phase? }\end{array}$ \\
\hline General Feedback & $\begin{array}{l}\text { What did you think of the programme overall? } \\
\text { What parts of the programme worked well/ could be improved? } \\
\text { What aspects of the programme do you think patients got most out of? }\end{array}$ \\
\hline Future Programmes & $\begin{array}{l}\text { Reflecting on the programme is there anything you would have done differently? } \\
\text { If you were to run this programme again how would you improve it? } \\
\text { When do you think would be the best time after a spinal cord injury to do a PMP? }\end{array}$ \\
\hline
\end{tabular}

\section{Phase 2: Semi-structured interviews and focus group}

Qualitative methodologies were used to explore the experiences of both individuals with SCI and clinicians who participated in the CBT-PMP.

Participants: A question schedule devised by the research team and informed by the current literature, explored participant's experience of the CBT-PMP. The battery of questions is summarised in Table 2. Voice-recorded, telephone semi-structured interviews took place two months post-intervention, allowing time for participants to reflect on the utility of the programme and to implement the CBT principles taught into daily life. Main areas explored feedback related to the PMP overall, changes in pain knowledge, attitude and management and alterations in quality of life, mood and sleep. Alternate options for delivering the programme (internet based) were also explored. Two researchers undertook the first interview (D.B, O.L), following which minor amendments were made to the question schedule, the remaining interviews were conducted by D.B.

Clinicians: A focus group with staff involved in the development and delivery of the SCI-PMP was undertaken three months post programme completion. The question schedule devised explored reflections on their experience of developing and delivering the SCI CBT-PMP (Table 2). The focus group was conducted by an experienced qualitative researcher (O.L) [40], who had no direct involvement in the development of the CBT-PMP.

\section{Analyses}

Quantitative data: Completed questionnaires from the three time points were coded, entered into SPSS Version 20 and cleaned. Participant characteristics were reported using descriptive statistics [mean (SD), median (range), frequency (percentage)]. Differences in study outcome measures over the three time points were analysed using a nonparametric Friedman test for related samples. Wilcoxon signed-rank tests explored whether significant differences exist in the pre-intervention ( $\mathrm{t} 1$ ), post-intervention ( $\mathrm{t} 2$ ) and the $\mathrm{t} 1$ and six month follow up (t3) scores respectively. Intention to treat analysis was employed when participants were lost to the six month follow up (t3), with last result (t2) carried forwards [41]. Significance was determined at $\mathrm{p}<0.05$.
Qualitative data: Post-intervention interviews were transcribed verbatim by the principal investigator (D.B) for independent, thematic analysis as per Braun and Clarke (2006) [42]. Analysis and reporting was guided by the Consolidated Criteria for Reporting Qualitative Research (COREQ) [43]. The qualitative dataset was formatted by referring to each speaker as ' $\mathrm{S}$ with a study number and referring to the line in which the comment occurred in the dataset as 'In'. Transcripts were re-read several times, with and without the corresponding recording. Comments were coded and themes were developed which captured the overall responses of participants and clinicians. Codes and themes were amalgamated based on similarities or were further differentiated to communicate separate ideas or comments [42]. Themes were reviewed to ensure accurate representation of the dataset, new themes were identified as required until data saturation occurred. A random sample of selected transcripts was reviewed for thematic inter-rater and intra-rater reliability. Intra-rater reliability was established by coding this dataset and re-coding it two days later (D.B). Inter-rater reliability of the coding scheme was achieved by two investigators (D.B, B.M.F) independently coding a random sample of the datasets and subsequently reviewing the dataset together [44].

\section{Results}

\section{Phase 1: Quantitative data: Outcome measures}

From 26 potential participants who fulfilled the inclusion criteria, eight (31\%) participated in and completed the programme. The main issues negatively affecting recruitment to the CBT-PMP included transport barriers (cost, access to a motor vehicle and in some cases the need for care giver accompaniment) and/or interference with work commitments and personal care plans.

Participant demographics are summarised in Table 3. The majority were male $(n=5,63 \%)$, with a mean (SD) age of $44(13.5)$ years and time post-injury of 8 (10.4) years. A thoracic level SCI was the most common diagnosis $(75 \%, n=6)$. All participants were wheelchair users.

Participants all successfully completed the programme with no adverse events recorded. The mean attendance rate was $89 \%$ (averaging 9 out of 10 sessions). At six month follow up (t3), three participants were uncontactable. Friedman's test for multiple 
Table 3: Characteristics of Participants.

\begin{tabular}{|c|c|}
\hline Variable & $n=8$ \\
\hline \multicolumn{2}{|l|}{ Age (years) } \\
\hline Mean (SD) & $44(13.5)$ \\
\hline \multicolumn{2}{|l|}{ Time post SCl (years) } \\
\hline \multirow[t]{2}{*}{ Mean (SD) } & $8(10.4)$ \\
\hline & n (\%) \\
\hline \multicolumn{2}{|l|}{ Gender } \\
\hline $\begin{array}{l}\text { Male } \\
\text { Female }\end{array}$ & $\begin{array}{l}5(63) \\
3(37)\end{array}$ \\
\hline \multicolumn{2}{|l|}{ Relationship Status } \\
\hline $\begin{array}{c}\text { Married } \\
\text { Single } \\
\text { In a relationship }\end{array}$ & $\begin{array}{l}6(75) \\
1(12) \\
1(12)\end{array}$ \\
\hline \multicolumn{2}{|l|}{ Employment Status } \\
\hline $\begin{array}{c}\text { Not working due to } \mathrm{SCl} \\
\text { Full time employment } \\
\text { Retired }\end{array}$ & $\begin{array}{l}6(75) \\
1(12) \\
1(12)\end{array}$ \\
\hline \multicolumn{2}{|l|}{ Cause of $\mathrm{SCl}$} \\
\hline $\begin{array}{l}\text { Road traffic accident } \\
\text { Fall } \\
\text { Medical }\end{array}$ & $\begin{array}{l}4(50) \\
2(25) \\
2(25)\end{array}$ \\
\hline \multicolumn{2}{|l|}{ Level of SCl } \\
\hline $\begin{array}{c}\text { C4 } \\
\text { T3 } \\
\text { T7 } \\
\text { T9 } \\
\text { T12 } \\
\text { L2 } \\
\text { Tetraplegia } \\
\text { Paraplegia }\end{array}$ & $\begin{array}{l}1(12) \\
2(25) \\
2(25) \\
1(12) \\
1(12) \\
1(12) \\
1(12) \\
7(88)\end{array}$ \\
\hline \multicolumn{2}{|l|}{ AIS Score } \\
\hline $\begin{array}{l}\text { AIS A (Complete) } \\
\text { AIS C (Incomplete) }\end{array}$ & $\begin{array}{l}7(88) \\
1(12)\end{array}$ \\
\hline \multicolumn{2}{|l|}{ Mobility Status } \\
\hline $\begin{array}{l}\text { Full time manual WC } \\
\text { Manual \& Electric WC }\end{array}$ & $\begin{array}{l}7(88) \\
1(12)\end{array}$ \\
\hline
\end{tabular}

AIS: American Spinal Injury Association Impairment Scale; WC: Wheelchair; SD: Standard Deviation.

comparisons of baseline (t1), post-intervention (t2) and six month follow up ( $\mathrm{t} 3$ ) scores (Table 4) demonstrated significant positive change across the three time points for the HADS depression score $\left(\mathrm{Chi}^{2}\right.$ 13.86; $\left.\mathrm{p}=0.01\right)$. Wilcoxon signed-rank tests compared scores between time points (Table 4). A significant difference was found in the psychological domain of the WHOQOL-BREF between $\mathrm{t} 1$ and $\mathrm{t} 2(\mathrm{Z}=-2.120 ; \mathrm{p}=0.03)$ but not between $\mathrm{t} 1$ and $\mathrm{t} 3$ indicating the immediate benefit identified was not sustained over time. On analysis, the HADS depression score showed significant differences between $\mathrm{t} 1$ and $\mathrm{t} 2(\mathrm{Z}=-2.555 ; \mathrm{p}=0.01)$ and between $\mathrm{t} 1$ and $\mathrm{t} 3(\mathrm{Z}=-2.533 ; \mathrm{p}=0.01)$ (Figure 1), indicating longer-term effects of the programme on mood. No significant differences were recorded in measures of sleep quality, pain intensity, pain interference or remaining WHOQOL-BREF domains.

\section{Phase 2: Qualitative data}

\section{a) Participant's feedback}

Six participants partook in semi-structured audio-taped telephone interviews. Interviews lasted between 11:07 minutes and 37:04 minutes. The coding tree is provided in Table 5 with both intra-

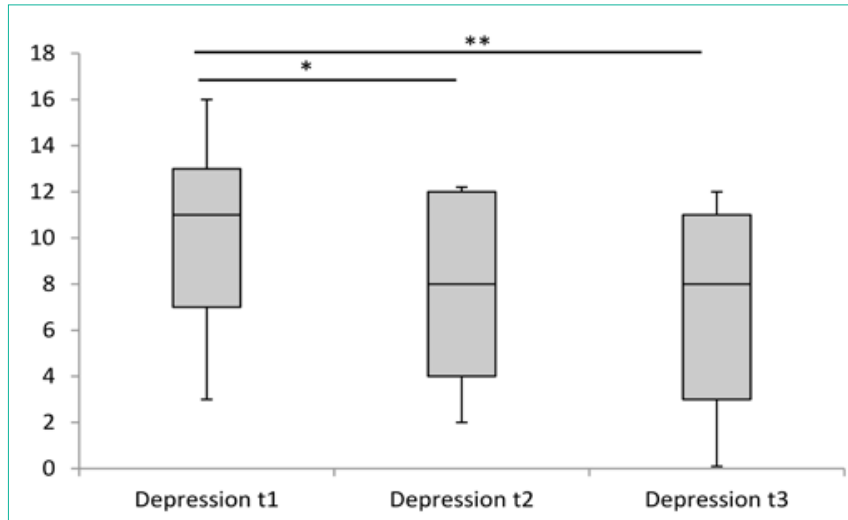

Significant difference in HADS depression at $\mathrm{t} 1$ and $\mathrm{t} 2(\mathrm{Z}=-2.555 ; \mathrm{p}=0.01)$ and ${ }^{\prime}$ between $\mathrm{t} 1$ and $\mathrm{t} 3(\mathrm{Z}=-2.533 ; \mathrm{p}=0.01)$.

$\mathrm{t} 1$; baseline, $\mathrm{t} 2$; post-intervention, $\mathrm{t} 3$; six month follow up.

Figure 1: HADS Depression Scores at $\mathrm{t} 1, \mathrm{t} 2$ and $\mathrm{t} 3$.

rater and inter-rater reliability of the coding system reaching $96 \%$. Four key themes were identified: (i) overall impression and impact of the programme, (ii) impact of support (peer and multidisciplinary team), (iii) changed perception and management of pain, (iv) future programme developments.

(i) Overall impression and impact of the programme: High levels of satisfaction were reported with content deemed relevant and applicable to managing SCI NP.

"All the information regards to pain wise how I felt and how others felt was quite accurate you know, I did find it quite helpful in some areas with regards to myself and how to put different things into practice to try and cope with pain (S4, In 518-20)".

Participants would recommend the programme to others.

"I would advise to everyone to take part because it was a good thing, it helped a lot to understand chronic pain and to cope with it $(S 2, \ln 275-6) "$.

Daily relaxation sessions were highlighted as beneficial with many incorporating the learned techniques into daily life.

"If I wake up now and in the middle of the night and it's there (pain) I know to do my breathing and that really helps" (S3, $\ln 406-7)$.

Physiotherapy sessions were another key CBT-PMP deemed beneficial.

"What I found ... what helps me is distraction so the exercise bit, the stretching bit that really helped" (S3, $\ln 438-439)$.

Participants reported positive mood changes after the programme which impacted personal relationships.

"I am not that angrier.my mood was very bad and I didn't want to go out with friends and it's much better now, definitely my mood is much better (S2, $\ln 238-240$ ).

Participants overall found the length of the programme to be an adequate duration for the programme.

"I think the five weeks was long enough, yeah definitely I think the 
Table 4: Baseline (t1), Post Intervention (t2) and Six Month Follow Up (t3) Comparisons of Outcome Measures.

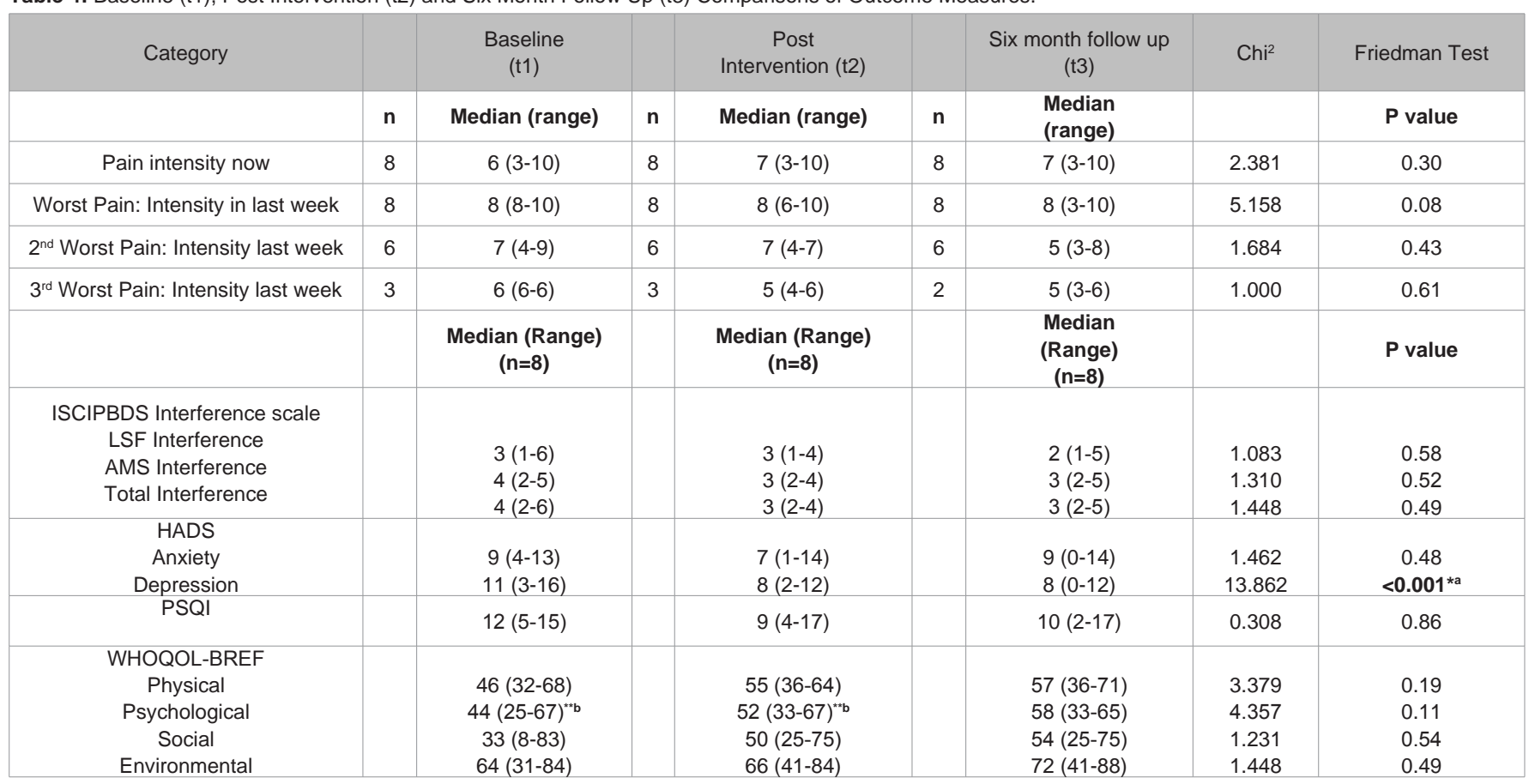

HADS: Hospital Anxiety and Depression Score; The International Spinal Cord Injury Pain Basic Data Set; N: Number; PSQI; Pittsburgh Sleep Quality Index; WHOQOLBref: World Health Organisation Quality of Life Bref.

${ }^{*} \mathrm{P}<0.05$; ${ }^{*}$ Significant difference in HADS depression at $\mathrm{t} 1$ and $\mathrm{t} 2(\mathrm{Z}=-2.555 ; \mathrm{p}=0.01)$ and between $\mathrm{t} 1$ and $\mathrm{t} 3(\mathrm{Z}=-2.533 ; \mathrm{p}=0.01)$; ${ }^{* * b}$ Significant difference in $\mathrm{Psychologica}$ domain of WHOQOL-Bref between $\mathrm{t} 1$ and $\mathrm{t} 2$ ( $\mathrm{Z}=-2.120 ; \mathrm{p}=0.03)$.

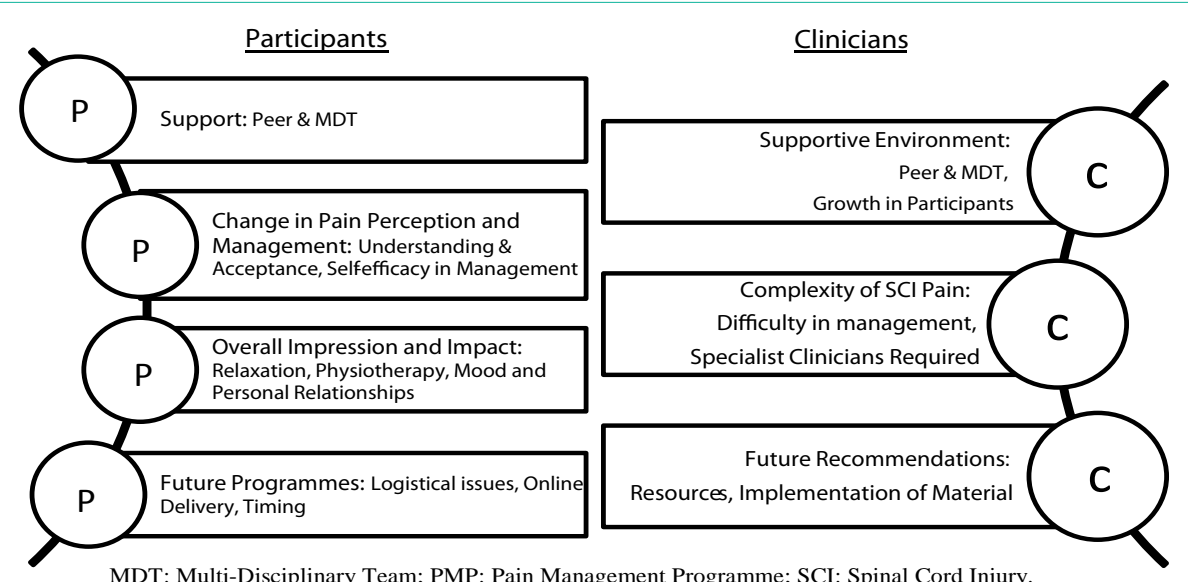

Table 5: Coding Tree of Interviews with Participants and Clinicians.

five weeks was fine" $(S 3, \ln 312)$.

ii) Support: This key theme demonstrated the beneficial impact of support on participants' engagement and enjoyment of the CBTPMP. The group setting allowed participants to learn from one another's experience of pain and understanding that they were not alone with their pain problem.

"I realised it's like bigger percentage of the people with spinal cord injuries having the same problem (pain) like me" (S1, ln 11-12).

"You see I find talking to somebody else in a wheelchair is therapy for me" (S3 Ln 453-454).

Participants found MDT knowledge and support in the CBT-
PMP helpful.

"It was good getting everybody from the different departments to have a chat... your nutritionist, your consultant, your pharmacist, physio and OT (occupational therapist). You know everybody getting involved was a really good thing" (S3, $\ln 469-471)$.

iii) Changed perception and management of pain: Participants reported an increased understanding and acceptance of ongoing pain following the CBT-PMP.

"Well I didn't know you have to be suffering with chronic pain for over three months before its chronic pain, you know I didn't really think I suffered from chronic pain" (S3, ln 480-482). 
"I understand the physiology of pain now.. it's universal and there's no quick fix. I also understand about flare ups and the triggers.. And that would actually help me to make sure to not get into a situation where you have flare ups (S6, In 1091-93).

Participants indicated they were now more accepting of their condition, and were motivated to manage it themselves rather than devolve responsibility to medical professionals.

"I was always under the impression that as soon as I go meet one of these people (pain specialists)..that they'd help me cure my pain... but now I'm coming to realise that the pain is probably going to be there for life and it's just the only person who is going to help me with it is myself" (S2, $\ln 220-223)$.

Participants reported increased self-efficacy in their ability to manage their pain and embed appropriate self-management strategies into their daily lives.

"I try to manage my diet better, to eat healthier things and do more exercises. Do the mindfulness and breathing exercises" (S1, ln 55-56).

"When a negative thought comes in I try and do the CBT and I'm more aware of it... in order to kind of just flip it over and change it over" (S3, ln 52-522).

iv) Future programme development: Participants stressed logistical difficulties travelling to the centre-based programme, suggesting onsite accommodation or more accessible methods of delivery for future programmes.

"By the time I got home the first couple of weeks I was shattered...it was a challenge getting up and down" (S2, ln 186-189).

"I guess like for me the biggest challenge was travelling" (S1, $\ln 27)$.

The utility of an internet-delivered CBT-PMP when suggested was seen as a worthwhile treatment option for those unable to attend a centre based programme.

"If there's nothing else they can do yeah the online would have to be the way to go" $(S 3, \ln 498)$.

However many suggested that the reduced peer support may be an issue with internet delivered CBT-PMPs.

"I think the face to face one and meeting up with people in the same boat as you that always helps... it makes it a bit easier to talk about it (pain) and share your information because other people are doing the same" (S4, ln 735-42).

Participants thought between six months to two years post-injury the best window for a CBT-PMP, to allow for adaptation to daily life with a SCI.

"I would imagine at least a year to a year and a half because when you get home from the hospital you're still trying to get just get your head around what's happened to you and just getting your head around how your life has changed" (S4, In 775-85).

\section{b) Clinician's feedback}

Seven of the eight clinicians involved in the delivery of the CBT-PMP (a clinical psychologist, two physiotherapists, two social workers, an occupational therapist and a rehabilitation consultant) participated in a semi-structured audio-taped focus group. The focus group lasted 57 minutes. Intra-rater reliability and inter-rater reliability of the coding system was $91 \%$ and $94 \%$ respectively. The coding tree is provided in Table 5. Three key themes emerged: i) the development of a supportive environment ii) the complexity of SCI pain and iii) future recommendations.

i) The development of a supportive environment: The clinicians noted that the MDT provided a supportive environment for the CBT-PMP. The diverse range of disciplines involved reinforced the primary message of the CBT-PMP, to promote the usefulness of selfmanagement techniques for the treatment of SCI NP.

"I think they felt the whole team, the whole spinal service at the NRH cared, about them and about pain, and I think that worked well" (S2, $\ln 233-6)$.

Peer support was noted to have created a relaxed learning environment for participants in which to begin to apply the principles of CBT to their pain management together.

"The peer support bit, the fact that they met each other and got together and supported each other" $(S 1, \ln 223-4)$.

"They definitely did learn they learned together, they learned from each other, they learned from us" (S2, In 495-6).

ii) The complexity of SCI pain: The clinicians highlighted the complexity of SCI pain and the challenges involved in its management due to physical disability and other co-morbidities associated with SCI.

"They possibly just see it as another part of the disability that they have, I have a SCI and I'm in a wheelchair and I have pain and it's all because of the fact that I've had a SCI... maybe they didn't do as much about it because they didn't see it as something they could tackle separate to their disability" $(S 7, \ln 315-9)$.

This again reinforced the need for specialised SCI CBTPMPs, delivered with input from experienced SCI rehabilitation clinicians who have expertise in SCI rehabilitation and chronic pain management.

"They were dealing with disability of which pain is a very big part, but they were dealing with disability and lots of other broad issues ...accessibility, attitudes, stereotypes, working, being in the community" $(S 2, \ln 387-91)$.

Clinicians reported further consolidation of their expertise in managing SCI pain following the programme with additional benefit from participation conferred to routine clinical practice.

"It does increase your comfort with something, you know it's (pain) definitely a bigger part of the dialogue probably with patients" (S2, In 557-8).

"I found it really interesting, I really enjoyed doing it... that might be the best thing to give them is that piece of education" (S3, $\ln 552-56)$.

iii) Future recommendations: Operational barriers to implementation identified included administrative burden, increased workload and associated pressures for the clinicians involved.

"There was more to the administrative and technical end to it than we would have expected" (S2, In 14). 
Future CBT-PMPs should include ring-fenced time for staff and increased application of programme material with community activities.

"I would have loved to have been able to allocate more time but it's eating away from your time with (other) patients and it's just a knock on effect" $(S 4, \ln 55-7)$.

"It would be important for them to have done the community piece so to go out and do something, be it going to a park for a push or bowling or something that they could access outside of here" $(S 3, \ln$ 666-670).

The benefit of onsite accommodation for participants was also highlighted.

"The utopian piece would be residential...overnights for all of them. And that would have increased the peer support bit" (S2, In 419-21).

\section{Discussion}

This mixed methods feasibility study highlights the benefits of implementing a five week multidisciplinary CBT-PMP specifically for NP after SCI. Significant improvements in participants' mood, postintervention and at the six month follow up were noted. Qualitative feedback highlighted improved pain acceptance, understanding and self-efficacy in pain management for participants. Transport to a centre based CBT-PMP proved challenging and impacted recruitment rates. Clinicians involved in programme delivery highlighted the complex nature of SCI chronic pain, confirmed their belief that specialised PMPs were required and outlined future recommendations for delivering these programmes. This study is unique when compared to other studies investigating CBT-PMPs post-SCI as it was significantly shorter in duration and captures, via qualitative methodology, extensive feedback from both service users (participants) and providers (MDT).

To date CBT-PMPs for SCI pain lasted eight weeks or longer in duration with significant positive changes recorded mainly in the psychological well-being of the participants [12,15-17], similar to findings of this current study. This demonstrates that a shorter intervention can also benefit participant's reported mood profiles. Limited qualitative feedback has investigated participants' views on optimal programme duration. Two studies both lasting 10 weeks, reported participants found the programme length adequate [16,17] Despite the brevity of this CBT-PMP, the in-depth qualitative feedback highlighted participants' high satisfaction in terms of programme duration and delivery, reporting positive change in understanding and acceptance of their pain condition, and demonstrating greater autonomy in pain self-management through implementing cognitive behavioural strategies into their daily lives. Additionally shorter, more condensed programmes may be more accessible and realistic for participants to attend, supported by the higher mean attendance rate recorded in this study when compared with that of Burns et al. (87\%) [15] and Heutink et al. (84\%) [26]. Clinicians noted increased work pressure and administrative duties while delivering the CBTPMP. Thus, shorter more condensed programme may again prove a more viable and sustainable option in SCI centres than the ten week CBT-PMPs previously tested.

This feasibility study highlighted barriers to implementation and sustainability of CBT-PMPs in SCI. Transportation costs, access to a motor vehicle and care giver accompaniment were highlighted as barriers to attendance. Norrbrink et al. [17], experienced similar recruitment difficulties and modified their CBT-PMP to include onsite accommodation. Such resources were unavailable in the current study. Furthermore, accompanying administrative burden and pressure on service delivery reported by the MDT underlines the requirement for dedicated personnel and resources for long-term viability of PMP initiatives. Chronic pain management services in the Republic of Ireland are limited and fall short of the recommendations by the International Association for the Study of Pain $[45,46]$. A potential solution to resource and transport barriers may be an internet delivered CBT-PMP. A recently published feasibility trial involving adults with SCI and mood disorders, demonstrated significant improvements in mood profiles following an online CBT programme versus waitlist controls [47]. Acceptability of an internet-delivered programme was explored in qualitative interviews with participants in this current study. Lack of peer support was highlighted as a potential concern, however it was considered a worthwhile treatment option where centre-based group programmes were inaccessible or unavailable. Internet delivered CBT-PMPs have shown promising effectiveness in other pain populations [48-50]. Addressing transport barriers and pressures on service delivery, online CBT-PMPs have potential to reduce costs and waiting times, increase privacy for participants and increase flexibility for users as the programme can be completed at any time and materials reviewed in one's own time $[48,50]$. Guidelines for NP management after SCI recommend that CBT-PMPs be specifically adapted for SCI and delivered by clinicians in specialist SCI rehabilitation centres [13,51]. Although increased pressure and administrative burden related to the programme was reported by clinicians in this current study, the clinical benefit was recognised. Clinicians highlighted that dual expertise was required both in pain science and SCI in CBT-PMP delivery to address the highly complex nature of SCI NP management which can be compounded by other secondary health complications including spasticity, pressure ulcers and low mood [52-54]. An Australian survey reported that $81 \%$ of health care professionals providing care for SCI patients in the community feel inadequately resourced to manage SCI pain, due to a lack of training, knowledge and specialist access [55]. It is note worthy therefore that clinician feedback highlighted a consolidation of their existing skillset in managing chronic pain post-SCI associated with delivering a CBT-PMP.

A limitation of this study was the small number of participants and the lack of a control group for comparison. Three quarters of the PMP participants engaged with the qualitative interviews, however data saturation of themes was achieved.

The benefits of CBT-PMPs for NP post-SCI reflect the literature for other chronic pain populations and these benefits are also conferred with a shorter, more intesive programme delivery. Due to the refractory nature of NP after SCI, CBT-PMPs warrant serious consideration as a minimal standard of care as they can allow individuals with SCI to better cope with and accept this long term, debillitating pain condition despite the human resource and cost burden associated with programme delivery.

\section{Acknowledgement}

The authors thank Ms Liz Maume, Ms Anu George, Ms Orlagh 
Murphy,Ms Kathleen Kelly, Ms Jayne Fitzherbert for their assistance in the delivery of the programme.

\section{References}

1. van Gorp S, Kessels AG, Joosten EA, van Kleef M, Patijn J. Pain prevalence and its determinants after spinal cord injury: a systematic review. European journal of pain (London, England). 2015; 19: 5-14.

2. Aito S, D'Andrea M, Werhagen L, Farsetti L, Cappelli S, Bandini B, et al Neurological and functional outcome in traumatic central cord syndrome. Spinal cord. 2007; 45: 292-297.

3. Haisma JA, van der Woude LH, Stam HJ, Bergen MP, Sluis TA, Post MW, et al. Complications following spinal cord injury: occurrence and risk factors in a longitudinal study during and after inpatient rehabilitation. Journal of rehabilitation medicine. 2007; 39: 393-398.

4. Westgren N, Levi R. Quality of life and traumatic spinal cord injury. Archives of physical medicine and rehabilitation. 1998; 79: 1433-1439.

5. Hoffman JM, Bombardier CH, Graves DE, Kalpakjian CZ, Krause JS. A longitudinal study of depression from 1 to 5 years after spinal cord injury. Archives of physical medicine and rehabilitation. 2011; 92: 411-418.

6. Norrbrink Budh C, Hultling C, Lundeberg T. Quality of sleep in individuals with spinal cord injury: a comparison between patients with and without pain. Spinal cord. 2005; 43: 85-95.

7. Bryce TN, Biering-Sorensen F, Finnerup NB, Cardenas DD, Defrin R Lundeberg $\mathrm{T}$, et al. International spinal cord injury pain classification: part I. Background and description. March 6-7, 2009. Spinal cord. 2012; 50: 413417.

8. Siddall PJ, McClelland JM, Rutkowski SB, Cousins MJ. A longitudinal study of the prevalence and characteristics of pain in the first 5 years following spinal cord injury. Pain. 2003; 103: 249-257.

9. Burke D, Fullen BM, Stokes D, Lennon O. Neuropathic pain prevalence following spinal cord injury: A systematic review and meta-analysis. Eur J Pain. 2017;21(1):29-44

10. Guy SD, Mehta S, Harvey D, Lau B, Middleton JW, O'Connell C, et al. The CanPain SCl Clinical Practice Guideline for Rehabilitation Management of Neuropathic Pain after Spinal Cord: recommendations for model systems of care. Spinal cord. 2016; 54: S24-S27

11. Williams Amanda CdC, Eccleston C, Morley S. Psychological therapies for the management of chronic pain (excluding headache) in adults. Cochrane Database of Systematic Reviews. 2012; 11.

12. Perry KN, Nicholas MK, Middleton J. Multidisciplinary cognitive behavioural pain management programmes for people with a spinal cord injury: design and implementation. Disability and rehabilitation. 2011; 33: 1272-1280.

13. Guy SD, Mehta S, Casalino A, Cote I, Kras-Dupuis A, Moulin DE, et al. The CanPain SCl Clinical Practice Guidelines for Rehabilitation Management of Neuropathic Pain after Spinal Cord: Recommendations for treatment. Spinal cord. 2016; 54: S14-S23.

14. Henwood P, Ellis J, Logan J, Dubouloz CJ, D'Eon J. Acceptance of chronic neuropathic pain in spinal cord injured persons: a qualitative approach. Pain management nursing: official journal of the American Society of Pain Management Nurses. 2012; 13: 215-222.

15. Burns AS, Delparte JJ, Ballantyne EC, Boschen KA. Evaluation of an interdisciplinary program for chronic pain after spinal cord injury. PM R: the journal of injury, function and rehabilitation. 2013; 5: 832-838.

16. Heutink M, Post MW, Bongers-Janssen HM, Dijkstra CA, Snoek GJ, Spijkerman DC, et al. The CONECSI trial: results of a randomized controlled trial of a multidisciplinary cognitive behavioral program for coping with chronic neuropathic pain after spinal cord injury. Pain. 2012; 153: 120-128.

17. Norrbrink Budh C, Kowalski J, Lundeberg T. A comprehensive pain management programme comprising educational, cognitive and behavioural interventions for neuropathic pain following spinal cord injury. Journal of rehabilitation medicine. 2006; 38: 172-180.
18. Perry KN, Nicholas MK, Middleton JW. Comparison of a pain management program with usual care in a pain management center for people with spinal cord injury-related chronic pain. The Clinical journal of pain. 2010; 26: 206 216.

19. Collett B, O'Mahoney S, Schofield P, Closs SJ, Potter J. The assessment of pain in older people. Clinical medicine (London, England). 2007; 7: 496-500.

20. Osborn M, Rodham K. Insights into Pain: A Review of Qualitative Research Reviews in pain. 2010; 4: 2-7.

21. Hearn JH, Cotter I, Fine P, K AF. Living with chronic neuropathic pain after spinal cord injury: an interpretative phenomenological analysis of community experience. Disability and rehabilitation. 2015; 37: 2203-2211.

22. Lofgren M, Norrbrink C. "But I know what works"--patients' experience of spinal cord injury neuropathic pain management. Disability and rehabilitation. 2012; 34: 2139-2147.

23. Mitchell LA, MacDonald RA. Qualitative research on pain. Current opinion in supportive and palliative care. 2009; 3: 131-135.

24. British Pain Society. Guidelines for Pain Management Programmes for Adults. British Pain Society. 2013.

25. Carnes D, Homer KE, Miles CL, Pincus T, Underwood M, Rahman A, et al. Effective delivery styles and content for self-management interventions for chronic musculoskeletal pain: a systematic literature review. The Clinical journal of pain. 2012; 28: 344-354.

26. Heutink M, Post MW, Bongers-Janssen HM, Dijkstra CA, Snoek GJ, Spijkerman DC, et al. The CONECSI trial: Results of a randomized controlled trial of a multidisciplinary cognitive behavioral program for coping with chronic neuropathic pain after spinal cord injury. Pain. 2012; 153: 120-128.

27. Kirshblum SC, Burns SP, Biering-Sorensen F, Donovan W, Graves DE, Jha A, et al. International standards for neurological classification of spinal cord injury (revised 2011). J Spinal Cord Med. 2011; 34: 535-546.

28. Fullen BM, Blake C, Horan S, Kelley V, Spencer O, Power CK. Ulysses: the effectiveness of a multidisciplinary cognitive behavioural pain managemen programme-an 8-year review. Irish journal of medical science. 2014; 183: 265-275

29. Fordyce WE. Behavioural methods for chronic pain and illness. St Louis.: Mosby. 1976

30. Turk DC, Meichenbaum D, Genest M. Pain and behavioural medicine: a cognitive behavioural perspective. New York: Guilford Press. 1983; 5: 148.

31. WHOQOL Group. Development of the World Health Organization WHOQOLBREF quality of life assessment. The WHOQOL Group. Psychological medicine. 1998; 28: 551-558.

32. Jang $\mathrm{Y}$, Hsieh $\mathrm{CL}$, Wang $\mathrm{YH}, \mathrm{Wu} \mathrm{YH}$. A validity study of the WHOQOL-BREF assessment in persons with traumatic spinal cord injury. Archives of physical medicine and rehabilitation. 2004; 85: 1890-1895

33. Lin MR, Hwang HF, Chen CY, Chiu WT. Comparisons of the brief form of the World Health Organization Quality of Life and Short Form-36 for persons with spinal cord injuries. American journal of physical medicine \& rehabilitation/ Association of Academic Physiatrists. 2007; 86: 104-113.

34. Hill MR, Noonan VK, Sakakibara BM, Miller WC. Quality of life instruments and definitions in individuals with spinal cord injury: a systematic review. Spinal cord. 2010; 48: 438-450.

35. Widerstrom-Noga E, Biering-Sorensen F, Bryce TN, Cardenas DD, Finnerup NB, Jensen MP, et al. The International Spinal Cord Injury Pain Basic Data Set (version 2.0). Spinal cord. 2014; 52: 282-286.

36. Zigmond AS, Snaith RP. The hospital anxiety and depression scale. Acta psychiatrica Scandinavica. 1983; 67: 361-370.

37. Woolrich RA, Kennedy P, Tasiemski T. A preliminary psychometric evaluation of the Hospital Anxiety and Depression Scale (HADS) in 963 people living with a spinal cord injury. Psychology, health \& medicine. 2006; 11: 80-90.

38. Buysse DJ, Reynolds CF $3^{\text {rd }}$, Monk TH, Berman SR, Kupfer DJ. The Pittsburgh Sleep Quality Index: a new instrument for psychiatric practice and 
research. Psychiatry research. 1989; 28: 193-213.

39. Sankari A, Bascom A, Oomman S, Badr MS. Sleep disordered breathing in chronic spinal cord injury. Journal of clinical sleep medicine: JCSM officia publication of the American Academy of Sleep Medicine. 2014; 10: 65-72.

40. Lennon OC, Doody C, Ni Choisdealbh C, Blake C. Barriers to healthy-lifestyle participation in stroke: consumer participation in secondary prevention design. International journal of rehabilitation research Internationale Zeitschrift fur Rehabilitations forschung Revue Internationale de recherches de readaptation. 2013; 36: 354-361.

41. Shao J, Zhong B. Last observation carry-forward and last observation analysis. Statistics in medicine. 2003; 22: 2429-2441.

42. Braun Va, Clarke V. Using thematic analysis in psychology. Qualitative Research in Psychology. 2006; 3: 77-101.

43. Tong A, Sainsbury $P$, Craig J. Consolidated criteria for reporting qualitative research (COREQ): a 32-item checklist for interviews and focus groups. International journal for quality in health care: journal of the International Society for Quality in Health Care/ISQua. 2007; 19: 349-357.

44. Silverman D. Qualitative Research-Theory Methods and Practice. $2^{\text {nd }}$ Edition ed: Sage Publications. 2004.

45. Fullen B, Hurley DA, Power C, Canavan D, O'Keeffe D. The need for a national strategy for chronic pain management in Ireland. Irish journal of medical science. 2006; 175: 68-73.

46. International Association for the Study of Pain. Recommendations for pain treatment services. 2009

47. Migliorini C, Sinclair A, Brown D, Tonge B, New P. A randomised contro trial of an Internet-based cognitive behaviour treatment for mood disorder in adults with chronic spinal cord injury. Spinal cord. 2016; 54: 695-701.
48. Bender JL, Radhakrishnan A, Diorio C, Englesakis M, Jadad AR. Can pain be managed through the Internet? A systematic review of randomized controlled trials. Pain. 2011; 152: 1740-1750.

49. Nevedal DC, Wang C, Oberleitner L, Schwartz S, Williams AM. Effects of an individually tailored Web-based chronic pain management program on pain severity, psychological health, and functioning. Journal of medical Internet research. 2013; 15: e201.

50. Macea DD, Gajos K, Daglia Calil YA, Fregni F. The efficacy of Web-based cognitive behavioral interventions for chronic pain: a systematic review and meta-analysis. The journal of pain: official journal of the American Pain Society. 2010; 11: 917-929

51. Multidisciplinary Association of Spinal Cord Injury Professionals (MASCIP) Guidelines for the Management of Neuropathic Pain in Adults following Spinal Cord Injury. 2008

52. Adriaansen JJ, Post MW, de Groot S, van Asbeck FW, Stolwijk-Swuste JM Tepper $\mathrm{M}$, et al. Secondary health conditions in persons with spinal cord injury: a longitudinal study from one to five years post-discharge. Journal of rehabilitation medicine. 2013; 45: 1016-1022.

53. Craig A, Guest R, Tran Y, Middleton J. Cognitive Impairment and Mood States after Spinal Cord Injury. J Neurotrauma. 2017; 34: 1156-1163.

54. Lundstrom U, Wahman K, Seiger A, Gray DB, Isaksson G, Lilja M. Participation in activities and secondary health complications among persons aging with traumatic spinal cord injury. Spinal cord. 2017; 55: 367-372.

55. ACI Pain Network \& NSW State Spinal Cord Injury Service. Chronic Pain \& Spinal Cord Injury Project Report 2: Clinician Needs Analysis. Chatswood, NSW: 2013.
Phys Med Rehabil Int - Volume 4 Issue 3 - 2017

ISSN : 2471-0377 | www.austinpublishing group.com

Burke et al. () All rights are reserved
Citation: Burke D, Lennon O, Nolan M, Psych DC, Barry S, Smith E, et al. A Cognitive Behavioural Therapy Pain Management Programme for Neuropathic Pain Post Spinal Cord Injury: A Feasibility Study Including the Clinician and Patient Perspectives. Phys Med Rehabil Int. 2017; 4(3): 1119. 